Note

\section{The Reactivity of 4-Thiouridine with Peroxidase and Superoxide Radicals}

\author{
Hitoshi Shibata, Hideo Ochial, \\ Manabu AkIYAMa, Hiroaki IshII \\ and Takashi KATOH
}

Laboratory of Biochemistry, College of Agriculture, Shimane University, Matsue, Shimane 690, Japan Received January 18, 1980

In 1946 Randall first noted that thiol compounds such as dithiouracil and thiourea were substrates for peroxidase. ${ }^{11}$ Recently horseradish peroxidase has been shown to catalyze the oxidation of some thiol compounds, dithiothreitol (DTT), cysteine and glutathione, in an oxygenconsuming reaction. ${ }^{2)}$ On the other hand superoxide radicals $\left(\mathrm{O}_{2}{ }^{-}\right)$can oxidize several thiol compounds ${ }^{37}$ and thiol groups occurring in papain.4)

A thiol-containing nucleoside, 4-thiouridine (4SU) occurs in $t$-RNAs of $E$. coli, ${ }^{5 \sim 8)} P$. aeruginosa $a^{6)}$ and so on. We reported that $4 \mathrm{SU}$ has an inhibitory effect on chloroplast development in greening plants. $\left.{ }^{9-11}\right)$ To examine the metabolic fate of $4 \mathrm{SU}$ in plants, we have studied the reactivity of $4 \mathrm{SU}$ in a peroxidase- $\mathrm{H}_{2} \mathrm{O}_{2}$ system and in $\mathrm{O}_{2}{ }^{-}$generating system. We report here an enzymatic oxidation of $4 \mathrm{SU}$ to bis $\left(4,4^{\prime}\right.$-dithiouridine) (4SSU) with horseradish peroxidase and also the reactivity of $4 S U$ and another thiolcontaining base, 6 -mercaptopurine (6MP) with $\mathrm{O}_{2}{ }^{-}$.

Oxidation of $4 S U$ with horseradish peroxidase. Figure 1 shows the spectral change occurred upon addition of $\mathrm{H}_{2} \mathrm{O}_{2}$ to the reaction mixture consisting of acetate buffer, $\mathrm{pH} 5.0$, peroxidase and $4 \mathrm{SU}$. The absorption spectrum of $4 \mathrm{SU}$ characteristic with a maximum at $331 \mathrm{~nm}$ was replaced by the one with two maxima of lower intensity at 310 and 260 $\mathrm{nm}$, which resembled that of authentic 4SSU prepared by the oxidation of $4 \mathrm{SU}$ in $\mathrm{KI}-\mathrm{I}_{2}$ solution. ${ }^{12)}$ On the addition of more $\mathrm{H}_{2} \mathrm{O}_{2}$ after $30 \mathrm{~min}$ of the reaction, no further changes in the spectrum were observed indicating a completed reaction. An isosbestic point appeared at $304 \mathrm{~nm}$. During the course of the reaction, no significant oxygen consumption was observed when monitored by a Clarktype oxygen electrode.

We found that on incubation with a reducing agent such as DTT or 2-mercaptoethanol, authentic 4 SSU was reduced to $4 \mathrm{SU}$, with a yield of $92 \sim 96 \%$. This reduction was also the case with the oxidation product of $4 \mathrm{SU}$ in the peroxidase $-\mathrm{H}_{2} \mathrm{O}_{2}$ reaction, but with a yield of $70 \sim 75 \%$. These results suggest that $4 \mathrm{SSU}$ is a product but not a sole. The formation of $4 \mathrm{SSU}$ and uridine as a by-product was

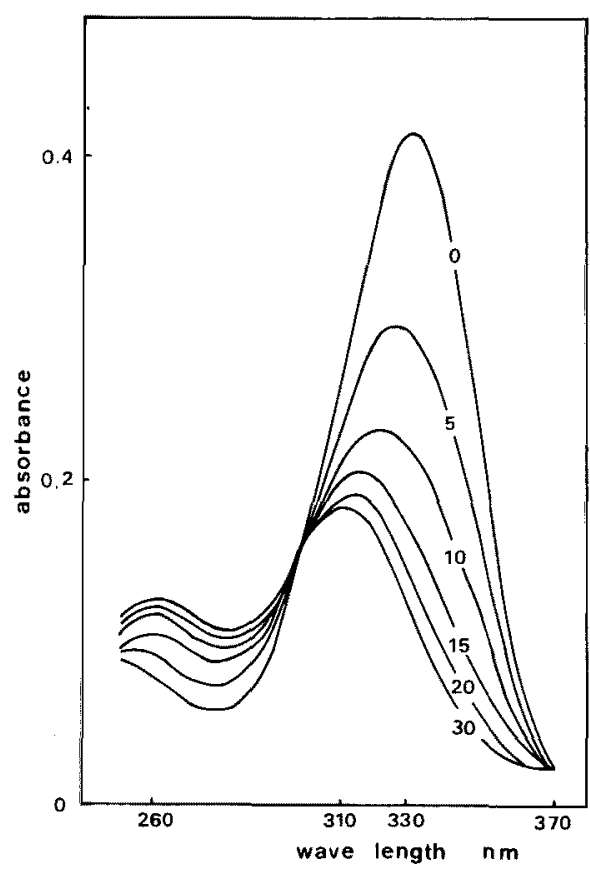

Fig. 1. Spectral Shift of $4 \mathrm{SU}$ by Horseradish Peroxidase.

The reaction mixture contained $0.05 \mathrm{M}$ acetate buffer, $\mathrm{pH}$ $5.0,20 \mu \mathrm{M} 4 \mathrm{SU}, 8.5 \mu \mathrm{M}$ horseradish peroxidase (Sigma, type II) and $600 \mu \mathrm{M} \mathrm{H} \mathrm{H}_{2}$ in a final volume of $2.0 \mathrm{ml}$. The reaction was started by the addition of $\mathrm{H}_{2} \mathrm{O}_{2}$. The numbers in the figure indicate reaction times in minute.

demonstrated by thin layer chromatography using the following solvent system; upper phase of 1-butanol-acetic acid-water, 4:1:5; ( $R f$ 4SSU, 0.30; uridine, 0.55; 4SU, 0.76 ) and by comparing UV spectra of the materials eluted from the plate with those of the authentic samples.

Since $\mathrm{H}_{2} \mathrm{O}_{2}$ has been reported to convert $4 \mathrm{SU}$ moiety in $t$ RNA to uridine, ${ }^{5,7)}$ we examined the non-enzymatic oxidation of $4 \mathrm{SU}$ by $\mathrm{H}_{2} \mathrm{O}_{2}$, i.e. in the absence of peroxidase. A significant decrease in absorption at $331 \mathrm{~nm}$ of $4 \mathrm{SU}$ was accompanied by an increase at $260 \mathrm{~nm}$. The result was interpreted as indicating that in the peroxidase- $\mathrm{H}_{2} \mathrm{O}_{2}$ system the enzymatic oxidation of $4 \mathrm{SU}$ is accompanied with its non-enzymatic oxidation to uridine. As a result, under the conditions used in Fig. 1, 40 nmol of 4SU was converted enzymatically to $17.4 \mathrm{nmol} 4 \mathrm{SSU}$ and nonenzymatically to $7.1 \mathrm{nmol}$ uridine.

Figure 2 shows the spectral changes in peroxidase which occurred during the course of $4 \mathrm{SU}$ oxidation at $\mathrm{pH} 7.0$. Ferriperoxidase spectrum, which has the familiar maxima at 403,495 and $640 \mathrm{~nm}$, did not change in the presence of 4SU (curve 1). The addition of $\mathrm{H}_{2} \mathrm{O}_{2}$ brought about a spectrum having three maxima at 418,530 and $555 \mathrm{~nm}$ and a shoulder between 610 and $620 \mathrm{~nm}$ (curve 2): the change implying the formation of peroxidase compound II. ${ }^{13)}$ 


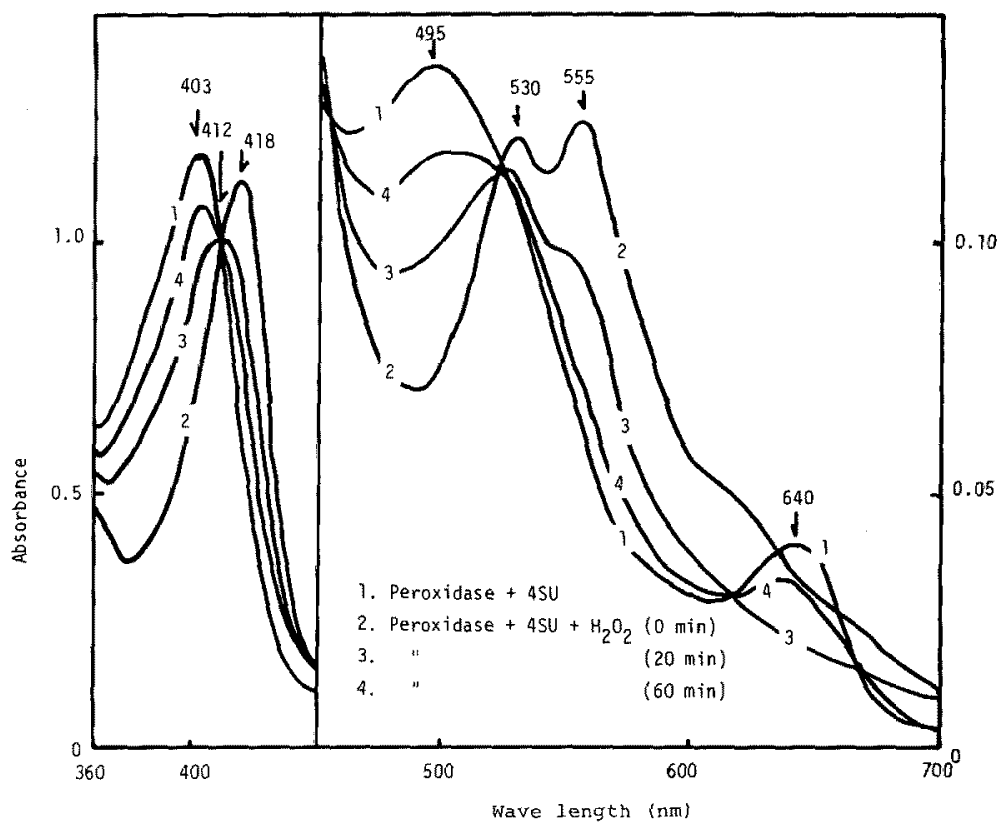

FIG. 2. Formation of Horseradish Peroxidase Compound II upon Addition of $4 \mathrm{SU}$ and $\mathrm{H}_{2} \mathrm{O}_{2}$.

The reaction mixture contained $0.05 \mathrm{~m}$ potassium phosphate, $\mathrm{pH} 7.0,40 \mu \mathrm{M} 4 \mathrm{SU}$ and $11.8 \mu \mathrm{M}$ horseradish peroxidase (curve 1). Curves $2 \sim 4$ represent absorption spectra at different times after the addition of $400 \mu \mathrm{M}$ $\mathrm{H}_{2} \mathrm{O}_{2}$ to the reaction mixture: curve 2, $0 \mathrm{~min}$; curve 3, $20 \mathrm{~min}$; curve 4, 60 min.

During the course of reaction with $4 \mathrm{SU}$, neither maximum at $543 \mathrm{~nm}$ nor shoulder near $579 \mathrm{~nm}$ appeared (curve $3 \sim 4$ ) suggesting that the compound $\mathbf{I I}$ is not involved in this reaction.

Generally, peroxidase catalysis is characterized by oneelectron oxidation of donor molecules. The free radicals derived from the donor through the one-electron reduction of the peroxidase compounds I and II are so reactive to be extinguished rapidly by disproportionation and dimerization. ${ }^{14 /}$ From the results that (1) the $4 S U$ oxidation in peroxidase- $\mathrm{H}_{2} \mathrm{O}_{2}$ system did not accompany oxygen consumption, (2) peroxidase compound III was not involved in the reaction, and (3) sodium metabisulfite $(40 \mu \mathrm{M})$, a radical scavenger, could inhibit the reaction completely, it follows that $4 S U$ thiyl radical formed by the peroxidase reaction may dimerize itself to produce $4 S S U$. This reaction mechanism is different from the one proposed for the peroxidase-catalyzed oxidation of DTT where $\mathrm{H}_{2} \mathrm{O}_{2}$ was not necessary and the stoichiometry observed was $1: 1$ for oxygen consumed to DTT oxidized.

Reactivity of $4 \mathrm{SU}$ with $\mathrm{O}_{2}{ }^{-}$. Alternatively the reactivity of $4 \mathrm{SU}$ with $\mathrm{O}_{2}{ }^{-}$was tested by examining the inhibition of epinephrine oxidation in a xanthine xanthine oxidase system $^{3)}$ No inhibition of epinephrine oxidation was observed by the addition of $2 \mathrm{mM} 4 \mathrm{SU}$ in the reaction mixture. A higher concentration of $4 S U$ interfered with the spectrophotometric assay. No cytochrome $c$ reduction was

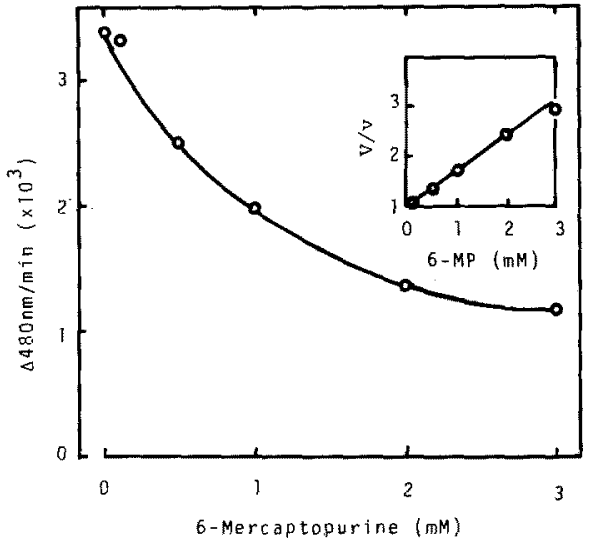

FiG. 3. Effect of 6MP Concentration on $\mathrm{O}_{2}{ }^{-}$-Induced Oxidation of Epinephrine.

The reaction mixture contained $0.05 \mathrm{M}$ potassium phosphate, pH 7.8, 0.5 mM epinephrine, $0.1 \mathrm{~mm}$ xanthine, $5 \mu \mathrm{g}$ of xanthine oxidase (Boehringer) and various concentrations of $6 \mathrm{MP}$, in a final volume of $1 \mathrm{ml}$. The reaction was started by the addition of xanthine oxidase. $V$ and $v$ were the oxidation rates of epinephrine in the absence and presence of $6 \mathrm{MP}$, respectively. 
inhibited in the presence of $1 \mathrm{~mm} 4 \mathrm{SU}$ in another $\mathrm{O}_{2}^{-}$generating system, illuminated chloroplasts. ${ }^{16)}$ These findings indicate that $4 \mathrm{SU}$ does not react with $\mathrm{O}_{2}{ }^{-}$at physiological $\mathrm{pH}$. However another thiol-containing nucleic acid base $6 \mathrm{MP}$ was reactive with $\mathrm{O}_{2}^{-}$. $6 \mathrm{MP}$ inhibited the oxidation of epinephrine by $\mathrm{O}_{2}{ }^{-}$. Figure 3 indicates the concentration effect of 6MP on the inhibition. A half inhibition of epinephrine oxidation was found at $1.4 \mathrm{~mm}$ under the present conditions. From the rate constant for the reaction between $\mathrm{O}_{2}^{-}$and epinephrine, $4 \times 10^{4} \mathrm{M}^{-1}$ $\sec ^{-1},{ }^{3)}$ and the slope of $\mathrm{V} / \mathrm{v}$ to the $6 \mathrm{MP}$ concentration, the second order rate constant for the reaction of $6 \mathrm{MP}$ with $\mathrm{O}_{2}{ }^{-}$was calculated to be $1.4 \times 10^{4} \mathrm{M}^{-1} \mathrm{sec}^{-1}$. The difference between $4 \mathrm{SU}$ and $6 \mathrm{MP}$ in the reactivity with $\mathrm{O}_{2}{ }^{-}$may be attributed to their structural difference: at $\mathrm{pH} 7.86 \mathrm{MP}$ essentially occurs in thiol form (lactim), while 4SU predominantly in thione form (lactam) because its $\mathrm{pKa}$ for enolization is $8.3{ }^{81}$ Thus, thiol-containing nucleoside existing in enolic form may be reactive with $\mathrm{O}_{2}{ }^{-}$as in the case with other thiol compounds.

The present results reveal that the oxidation of $4 \mathrm{SU}$ by peroxidase is not beyond the bounds of possibility in plant cells: however, the reaction of $4 \mathrm{SU}$ with $\mathrm{O}_{2}{ }^{-}$is unlikely to occur. The metabolism of $4 \mathrm{SU}$ in radish seedlings will be reported elsewhere.

\section{REFERENCES}

1) L. O. Randall, J. Biol. Chem., 164, 521 (1946).
2) J. Olsen and L. Davis, Biochim. Biophys. Acta, 445, 324 (1976).

3) K. Asada and S. Kanematsu, Agric. Biol. Chem., 40, 1891 (1976).

4) W. S. Lin, J. R. Clement, G. M. Gaucher and D. A. Armstrong, Rad Res., 62, 438 (1975),

5) L. Shugart, Arch. Biochem. Biophys., 148, 488 (1972).

6) Y. S. P. Rao and J. D. Cherayil, Biochim. Biophys. Acta, 299, 1 (1973).

7) Y.S. P. Rao and J. D. Cherayil, Biochem. J., 143, 285 (1974).

8) M. N. Lipsett, J. Biol. Chem., 240, 3975 (1965).

9) H. Ochiai and H. Shibata, Agric. Biol. Chem., 34, 1751 (1970)

10) H. Ochiai, H. Shibata and T. Suekane, ibid., 35, 1259 (1971).

11) H. Shibata and H. Ochiai, ibid., 37, 471 (1973).

12) E. B. Ziff and J. R. Fresco, J. Am. Chem. Soc., 90, 7338 (1968).

13) W. E. Blumberg, J. Peisach, B. A. Wittenberg and J. B. Wittenberg, J. Biol. Chem., 243, 1854 (1968).

14) I. Yamazaki, "Molecular Mechanisms of Oxygen Activation," ed. by O. Hayaishi, Academic Press Inc., New York, N.Y., 1974, p. 535.

15) L. R. Fox, W. K. Purves and H. I. Nakada, Biochemistry, 4, 2754 (1965).

16) K. Asada, K. Kiso and K. Yoshikawa, J. Biol. Chem., 249, 2175 (1974). 